www.jmscr.igmpublication.org

Impact Factor (SJIF): 6.379

Index Copernicus Value: 71.58

ISSN (e)-2347-176x ISSN (p) 2455-0450

crossref DOI: https://dx.doi.org/10.18535/jmscr/v6i2.70

Journal Of Medical Science And Clinical Research

\title{
Spontaneous Rupture of Papillary Renal Cell Carcinoma: A Rare Presentation
}

\author{
Authors \\ Dr Shriyansh Chahar, Dr Suresh Bhat, Dr Fredrick Paul, Dr Mahesh MS \\ GMC Kottayam
}

\begin{abstract}
A 38 year-old hypertensive male patient presented with left flank swelling and pain of 2 days duration. Evaluation of the patient revealed a large left renal subcapsular hematoma with poorly functioning left kidney. Left nephrectomy was performed. Histopathology revealed papillary renal cell carcinoma.

Keywords: spontaneous renal hemorrhage, papillary renal cell carcinoma.
\end{abstract}

\section{Introduction}

Spontaneous rupture of renal parenchyma is uncommon, usually seen as a complication of an existing underlying pathology. The common causes are benign and malignant tumours of the kidney, angiomyolipoma and renal cell carcinoma being the most common causes. The patients are usually elderly and present with severe abdominal pain, abdominal mass and shock (Lenk's triad). On imaging, usually the renal pathology is identified and patient is managed conservatively or with angioembolisation.

Papillary renal cell carcinoma (pRCC) is the second most common type of RCC and is asymptomatic in $40 \%$ of patients. Signs and symptoms are very similar to those of more common clear cell carcinoma. Our patient is unique in that imaging did not show any underlying renal mass and it was an incidental histopathological finding.

\section{Case Report}

A 38-year-old hypertensive male patient presented with left flank swelling and pain of 2 days duration. Physical examination revealed a well defined ballotable mass in left hypochondrium which was mildly tender. Routine investigations showed $\mathrm{Hb} \%$ - $12.3 \mathrm{gm} \%$, total count 8200 cells/cumm, serum creatinine - $1.2 \mathrm{mg} / \mathrm{dl}$, Urine culture did not grow any organism. Ultrasonography (USG) Abdomen showed a large left renal subcapsular collection of size $17.9 \mathrm{x}$ $14.8 \times 8.4 \mathrm{~cm}$ with possibility of hematoma. Contrast enhanced computed tomography (CECT) showed large subcapsular collection with blood clots $(11.2 \times 10.8 \times 14 \mathrm{~cm})$ compressing and distorting the left renal parenchyma with no evidence of underlying neoplastic lesion (Fig-I \& Fig-II). DTPA Renal Scintigraphy showed that the left kidney had only $8 \%$ of the differential function with $6.1 \mathrm{ml} / \mathrm{sec}$ GFR. Left simple nephrectomy was performed with a diagnosis of left renal subcapsular hematoma with poorly 
functioning kidney. Intra operatively, around 2.5 litre of boold stained fluid was drained from around the left kidney. Left kidney was necrotic and friable with dense adhesions between renal capsule and peritoneum and psoas muscle. Grossly, the surface of specimen showed cystic spaces and necrotic areas. Histopathologicaly, cut section showed a grey white growth measuring $7.5 \times 4.5 \times 4 \mathrm{~cm}$. Adjacent areas showed cystic degeneration. Microscopically, section showed renal tissue with an infiltrating neoplasm arising from it in the form of papiilae, tubules and cords. Individual cells were cuboidal to polygonal with abundant eosinophilic papillary renal cell carcinoma cytoplasm. Stroma showed necrosis, hemorrhage and lymphoplasmacytic infiltrate. The neoplasm infiltrated the renal capsule, perirenal fat and renal sinus. The final impression of the histopathological report was that of a Papillary Renal Cell Carcinoma with Fuhrman's grade 4 (Fig-III).

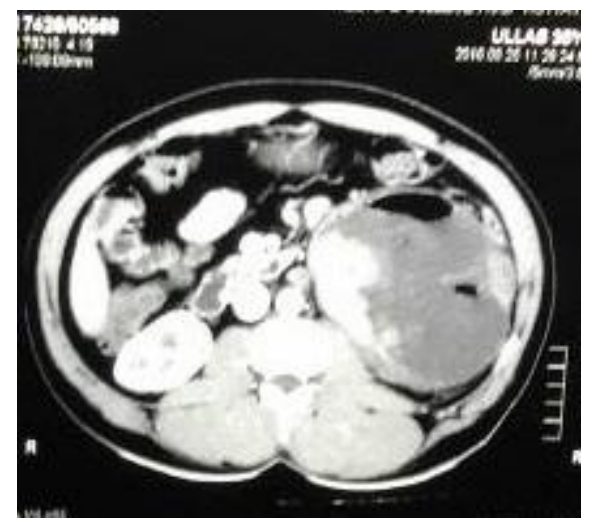

Fig-I

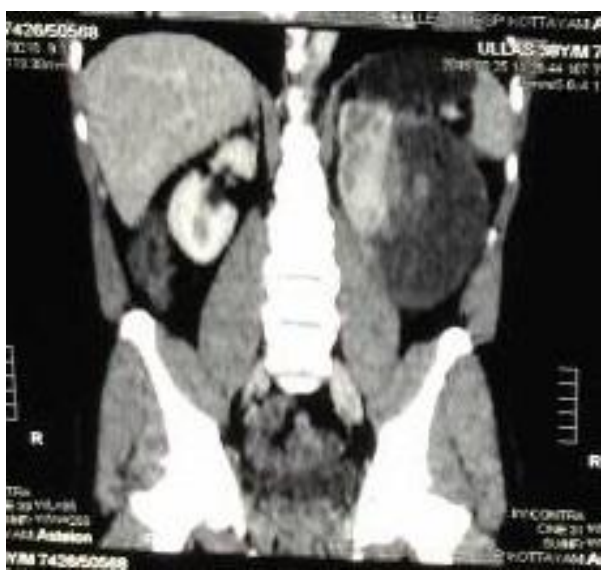

Fig-II

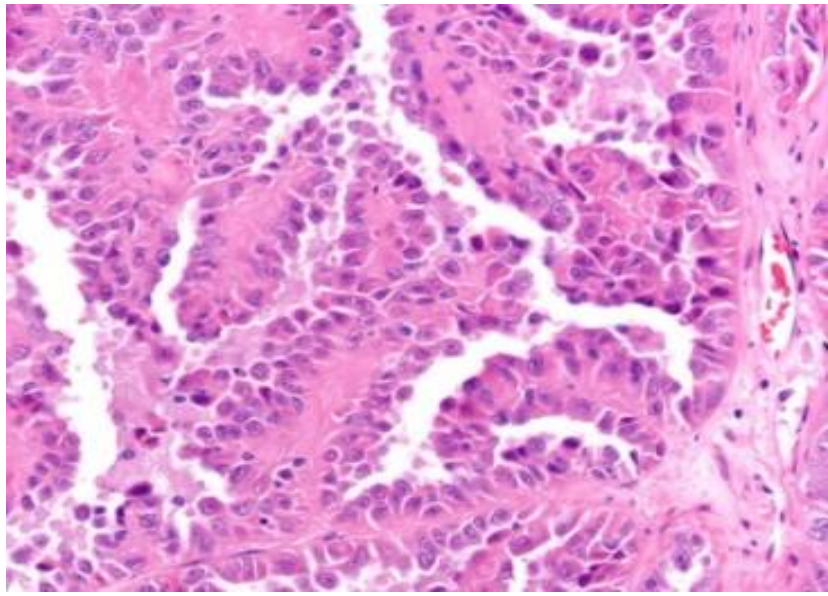

Fig-III

\section{Discussion}

Spontaneous renal hematoma was initially reported by Bonet in $1679^{3}$ and was later on described by Wunderlich in $1856^{4}$. Clinically, patients may present with various manifestations including symptoms of acute flank pain, abdominal mass and shock (Lenk's triad) ${ }^{5}$.

Ultrasound is a very usefull investigation for early and rapid identification of the condition. CT scan is used to confirm the findings of USG. It is $100 \%$ sensitive for diagnosis. It gives valuable information regarding the cause of hematoma. It has higher sensitivity and specificity than ultrasound for identification of an underlying mass $^{2}$. Magnetic resonance imaging (MRI) is a useful alternative to $\mathrm{CT}$ scan. If the imaging modalities are unable to find the cause, then angiography should be judicially performed ${ }^{6}$.

Non-traumatic spontaneous rupture of renal parenchyma is rare but life-threatening condition. The most common underlying cause of spontaneous renal hemorrhage are the benign and the malignant renal tumours (61\%). Angiomyolipoma is the most common cause $(29 \%)$ with renal cell carcinoma being the second most common cause $(26 \%)^{1}$. Vascualar diseases like Polyarteritis Nodosa (PAN) are the second most common cause of this pathology $(17-18 \%)^{2}$. About $7 \%$ cases are idiopathic ${ }^{2}$.

Treatment strategies of such patients have been a topic of discussion. Kendall et al. proposed radical nephrectomy as a treatment of such conditions 
where there is no apparent etiology and normal contralateral kidney with careful pathological examination because of high incidence of small renal tumors ${ }^{7}$. Bosniak et al. even claimed that operative exploration is not necessary in most unexplained cases because of the diagnostic accuracy of CT scan using $5 \mathrm{~mm}$ sections and contrast medium $^{8}$. Serial CT scans are taken until the hematoma is resolved and the underlying pathology becomes evident.

Several mechanisms of tumour rupture have been proposed. Amongst the prevelant theories are those of direct tumoral invasion of capsular or vascular structures ${ }^{9}$; due to tension as a result of increased renal venous pressure depending on tumoral emboli ${ }^{1}$ and necrosis depending on the growth of the tumor ${ }^{10}$.

Papillary renal cell carcinoma (pRCC) is the second most common type of malignant renal epithelial tumor ${ }^{11}$. There are two histological types of papillary renal cell carcinoma with different prognosis. Type I is more frequently multifocal, it is made of papillae covered by small cells with modest cytoplasm, with a low nuclear grade, and dislocated in one single layer upon the papillae basement membrane; Type II is made of papillae covered by cells with eosinophilyc cytoplasm $^{12}$. Prognosis is better for type I pRCC than type II pRCC, but it is anyway related to the tumoral grade, to the tumoral stage and to the diagnostic precocity ${ }^{13}$.

pRCC is predominantly a pathology of elderly people. Such patients have chronic renal failure in $40 \%$ cases $^{14}$. Signs and symptoms are non-specific and usually resemble to those of the more common clear cell renal cell carcinoma. $40 \%$ of the cases are asymptomatic. Microscopically, pRCCs were predominantly papillary or tubopapillary, often with foam cells, necrosis, hemorrhage and multifocality ${ }^{15}$. Many studies have confirmed the more aggressive nature of the Type II pRCC and the predominance of these tumours in the elderly population. Also, the multifocal nature of these tumours have been emphasized in various reports.
Our patient is unique in a way that he was very young at the time of presentation and that he did not show any signs and symptoms of an underlying malignancy prior to the short duration of non-specific symptoms. The diagnosis of pRCC as made only after the histopathogical examination of the nephrectomy specimen which in turn also revealed a non-multifocal pRCC which is also a very rare feature of pRCC.

\section{Conclusion}

Non-traumatic rupture of renal parenchyma is a rare phenomenon with the angiomyolipoma to be the most common etiological entity closely followed by renal cell carcinoma. CT is the method of choice for evaluation of perirenal hemorrhage, although its sensitivity for detection of underlying etiology is only moderate. Case reports of multifocal papillary renal cell carcinoma, in the literature, have been described. To our knowledge, this is the first case of spontaneous rupture of the kidney affected by unifocal papillary renal cell carcinoma in literature without showing earlier specific cancer signs and symptoms

\section{References:}

1. Kim WB, Lee ES, Doo SW, et al. Spontaneously ruptured renal cell carcinoma during hemodialysis in two patients with end-stage renal disease. Korean J Urol. 2011;52:865-7.

2. Zhang JQ, Fielding JR, Zou KH. Etiology of spontaneous perirenal hemorrhage: a meta-analysis. J Urol. 2002;167:1593-6.

3. Bonet T. Sepulchretum, sive anatomiapractica ex cadaverbius morbobdenatis. Geneva: L Chouet; 1679.

4. Wunderlich CR. Handbuck der Pathologie und Therapie. In: Polkey Vynalek., editor. 2nd ed. Stuttgart, Ebner and Seubert: 1856.

5. Orr WA, Gillenwater JY. Hypernephroma presenting as an acute abdomen Surgery. 1971;70:656. 
6. Brkovic D, Moehring $\mathrm{K}$, Doersam J, Pomer S, Kaelble T, Riedasch G, et al. Diagnosis and management of spontaneous perirenal haematomas. Eur Urol. 1996;29:302-7.

7. Kendall AR, Senay BA, Coll ME. Spontaneous subcapsular renal hematoma: Diagnosis and management. J Urol. 1988; 139:246-50.

8. Bosniak MA. Spontaneous subcapsular and perirenal hematomas. Radiology 1989;172:601-2.

9. Polky HJ, Vynalek WJ. Spontaneous nontraumatic perirenal and renal hematomas. Arch Surg. 1933;26:196-218.

10. Mydlo JH, Kaplan J, Thelmo W, et al. Spontaneous renal hemorrhage associated with renal tumors. Clin Imaging. 1997 21:287-9.

11. Kosaka T, Mikami S, Miyajima A, et al. Papillary renal cell carcinoma: clinicpathological characteristics in 40 patients Clin Exp Nephrol 2008;12:195-9.]

12. Bhatnagar R, Alexiev BA. Renal-cell carcinomas in end-stage kidneys: a clinicopathological study with emphasis on clear-cell papillary renal-cell carcinoma and acquired cystic kidney diseaseassociated carcinoma. Int J Surg Pathol 2012;20:19-28.

13. Ross H, Martignoni G, Argani P. Renal cell carcinoma with clear cell and papillary features. Arch Pathol Lab Med 2012; 136:391-9.

14. Goyal R, Gersbach E, Yang XJ, Rohan SM. Differential diagnosis of renal tumors with clear cytoplasm. Arch Pathol Lab Med 2013;137:467-80.

15. Yamada T, Endo M, Tsuboi $M$, et al. Differentiation of pathologic subtytes of papillary renal cell carcinoma on CT. AJR Am J Roentgenol 2008; 191:1559-63. 